\title{
Unresectable Ureter Urothelial
} Carcinoma

National Cancer Institute

\section{Source}

National Cancer Institute. Unresectable Ureter Urothelial Carcinoma. NCI Thesaurus.

Code C158587.

Ureter urothelial carcinoma that is not amenable to surgical resection. 